\title{
Reconciling Expert Advice and Community Opinion in a Local Government Strategic Planning Process
}

\author{
Ken Simpson \\ Phil Bretherton
}

This article proposes that the eventual outcomes of local government strategic policy deliberations can often reflect the interplay between "expert" administrative staff, democratically elected politicians, and the community they jointly serve. A multi-site case study approach, to examine the generation of local government strategy related to a niche economic activity concludes that broadly conceptualized opinion congruence can sometimes be threatened by substantial pockets of stakeholder vested interest. As such, "expert" and "political" opinion reflects a caution based on both historical experience and political expediency; while community opinion displays an optimism based on eager anticipation of an unknown future.

Keywords: local government, strategic planning, community consultation, tourism

\section{INTRODUCTION}

The latter part of the 20th century has seen the emergence of rapid, fundamental, and sometimes contradictory change in the philosophies and processes used to determine the strategic planning mechanisms of local government in Western democracies. The "New Public Management" approach was introduced in the 1980s in response to perceived deficiencies in contemporary management practice, with an emphasis on improved efficiencies, controlled costs, and increased cognizance of what were rather vaguely referred to as "competitive market forces" (Newton \& van Deth, 2005). At the same time, the Blair government's professed desire to find a form of political middle ground, between conservative capitalism and liberal socialism, attempted to partner an overtly commercial and managerial stance with a complementary promotion of citizen-driven democracy through the principles of community governance (Reddel, 2004).

Though much has been written about the substantial cultural changes these initiatives have introduced into the local government environment, and a similar level of attention paid to the real and potential costs and benefits of change implementation, this article contends that much of the impact of those changes can be captured through a focus on evolving relationships between three key actors in the local government domain:

- the "experts": permanent salaried staff of local authorities

- the "politicians": democratically elected representatives of locally resident people

- the "community": (individual and collective) residents who both contribute to and benefit from the provision of local government services.

Traditionally, as Figure 1 shows, this relationship has reflected a complex pattern of tensions between the ability of salaried staff to apply their professional expertise to the planned development of a spatially defined community; the desire of local residents to access a 
maximized range of local services at minimum possible cost; and the efforts of elected politicians to reconcile the wishes of paid professional planners with the demands of enfranchised community residents-in other words, to balance technical effectiveness with political legitimacy in the interests of continued popularity and consequent re-election (Silver, Weitzman, \& Brecher, 2002). There is little doubt that the changing face of public administration has been reflected in a corresponding adjustment to the conventionally accepted balance of power between these three entities.

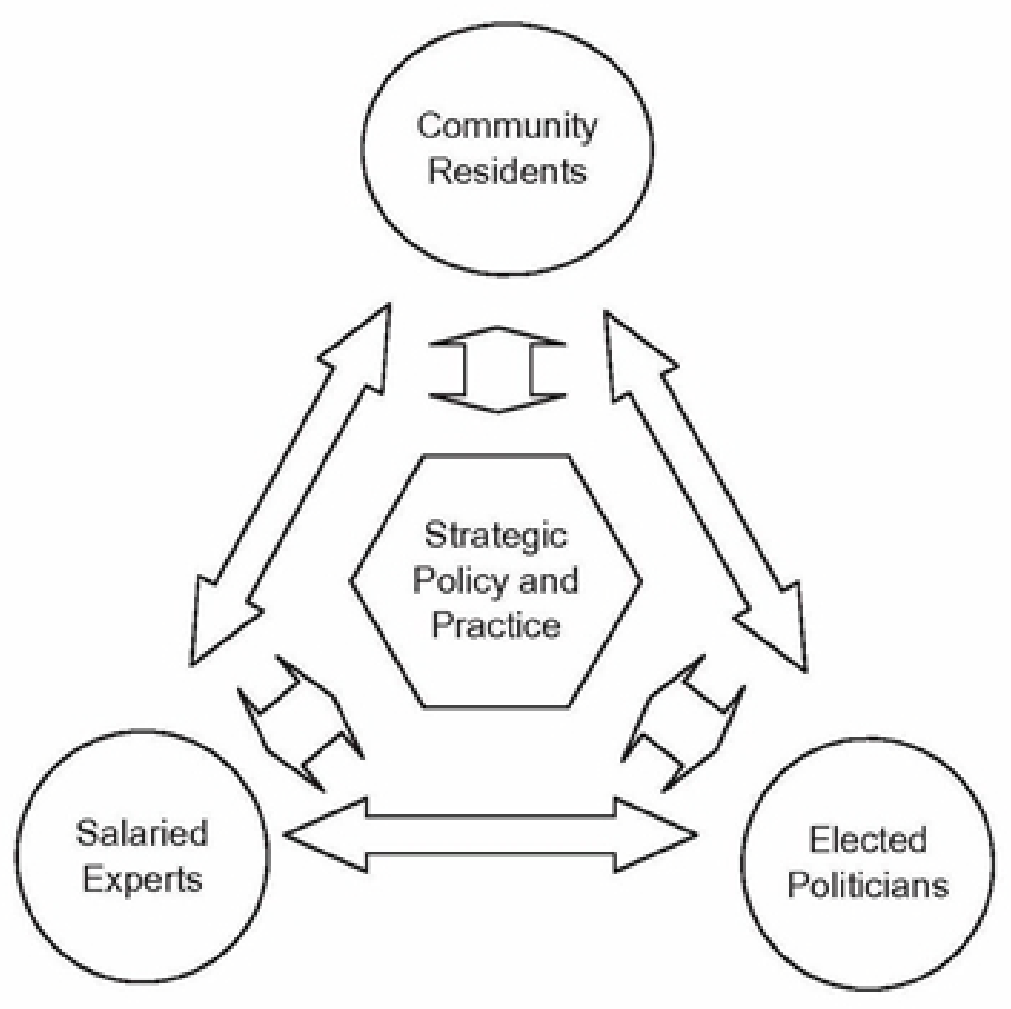

FIGURE 1 Stakeholder influences on local government strategy.

Though it has been historically fair to portray the expert and political corners of the Figure 1 triangle as protagonists in an ongoing debate about how best to develop and deliver local services to a largely passive "community" corner, that perspective has now been considerably adjusted. In the Western world at least, the 21st century picture is increasingly reflective of more direct interaction between expert and community, mediated and moderated by locally elected politicians - seen by the experts as the voice of community, and seen by community as the supervisory managers of those experts (Reddel \& Woolcock, 2004).

The specific nature of these relationships does of course vary on a case-by-case basis, with pragmatic reality continuing to play an important role in reconciling the technician-based view of salaried public servants with the politically driven perspective of elected members. Similarly, community opinion related to the effectiveness of elected representatives can range widely, from 
enthusiastically supportive to cynically dismissive, perhaps reflecting more on the concept of political acumen than that of managerial competence. As such, in terms of its value in securing significant stakeholder agreement related to strategic planning at local level, the Figure 1 triangle has been proven to work best when the expert and community voices are largely in accord (Barbaro, 2006). The primary focus of this article is to examine the extent to which that level of accord might reasonably be expected to exist in practice.

In this context, the article investigates the issue of expert-community interactions in the determination of local government strategy related to future investment in tourist/ visitor facilities in small city environments. For many such cities, massive structural change wrought by the continuing globalization of industry has led to major economic shifts, as once dominant industries recede in relative importance, and as major local employers relocate elsewhere in search of resource costs savings. In circumstances such as these, small- and medium-sized communities have increasingly found themselves searching for economic salvation through the development of a local tourism industry, for there are often few alternative avenues to support the preservation of local culture and lifestyle.

Local government administrations with strategic planning responsibility for those communities seldom possess an established internal expertise related to tourism development, and our case study investigations suggest that they will often seek external assistance through both formal and informal consultation with key informant groups-relevant central government departments, regional development agencies, local chambers of commerce, existing tourism operators, and other stakeholders with a perceived interest in the future of local tourism. Given that these agencies will often share a developmental perspective related to the community's optimum future, it is reasonable to suppose that a jointly endorsed course of action, reflecting both technical expertise and acknowledged self-interest, can emerge from what can often be a "coalition of the willing." In these circumstances, informally negotiated agreement can quickly become formally adopted policy in a very short period of time.

This article has taken an international approach to assessing the extent to which local community attitudes to tourism coincide with the type of negotiated consensus referred to above. As such, a parallel program of research activity was undertaken in three small cities in England, Ireland, and New Zealand, in an effort to first establish the extent to which any form of "expert assessment" could be determined in relation to each community's potential as a tourism destination; and second, to canvas the views of ordinary local residents to establish the degree to which grassroots local opinion coincided with the expert view. The outcomes of this research are expected to be of interest to all stakeholders in such early-stage tourism development communities, but more specifically to those who are entrusted with the responsibility of delivering a desired and desirable future to the community and its residents.

\section{EXPERT ADVICE AND COMMUNITY CONSULTATION}

Fagan (2006) notes that local government agencies can, to some extent, be represented as social engineers, in that their values, vision, strategies, and subsequent actions will inevitably leave a permanent imprint on the ways in which local economies and societies develop. As such, the relative influence of permanent staff, elected representatives, and community citizens will in turn impact on the character of local government performance, ranging from a consistent commitment 
to economic "development at all costs" on the one hand, and a conscious adherence to ecosustainable society on the other (Saunders, 2002). The stance taken by any individual authority, and its subsequent level of commitment to community consultation, can often reflect that authority’s positioning on a nominal “develop-sustain” continuum.

Though the format of local community consultation is frequently mandated by central government legislation, there is often a considerable flexibility in the extent to which local administrations respond to their statutorily determined obligations. At one end of the scale, the required consultative process may be treated as a compliance issue, with minimum possible response levels selected; at the other, statutory requirements may be seen as a useful justification for a comprehensive and holistic program of citizen engagement.

However, as Donnelly (1999) has noted, the majority view has quite clearly tended towards the former option, reacting to an ever-expanding volume of "government guidelines" with an unspoken resolve to "do only what we have to do." As such, rather than representing a genuinely focused effort to enter into dialogue with residents, consultation can degenerate into a process of "ticking the required boxes" so that internal and external auditors may satisfy themselves that due process has been followed.

As central governments continue to encourage the movement of local consultation practice as far as possible along the "inform-consult-involve-collaborate-empower" framework of the International Association for Public Participation (2007), contemporary attitudes towards what might constitute "appropriate” strategic development move ever closer to a vision of the local area "as local residents would like to see it." This in turn generates a resurgence of what has been a never-ending debate in political circles - to what extent should governments give people what they want, and to what extent what they need - and a battery of associated philosophical questions:

- Who are the most appropriate decision makers in the community-whose wishes should strategic directions reflect?

- Who are the most capable decision makers in the community — who has the talent and ability?

- Who are the legislatively determined decision makers in the community-who has the power and authority?

- How much influence does each of these groups have on the strategy process?

- How can we best align their thinking so that optimal decisions emerge?

In this respect, Silver et al. (2002) note that many local government programs need to incorporate the views of technical experts, as well as ordinary community residents, and that a strenuous effort to reconcile these two sets of opinion will be rewarded in terms of an enhanced local government commitment to democracy, an increased level of support from ordinary citizens and, ultimately, a higher level of trust in the machinery of local government. In pursuit of effective reconciliation of these perspectives, Silver et al. suggest a three step investigative process: 
- What are expert and community opinions?

- To what extent do these opinions coincide and differ?

- How can differences best be reconciled?

The paragraphs that follow take a case study approach to the application of these questions to three individual study sites.

\section{STUDY SITES}

In order to meet the overall objectives of a wider omnibus-style survey project, it was deemed desirable to conduct this research in three reasonably comparable communities that nevertheless reflected varying stages of tourism development intensity. As such, the communities of Buxton (England), Waterford (Ireland), and Whangarei (New Zealand) were selected as broadly comparable entities that differed substantially in terms of their status as a tourism destination. Thus, all three communities are presented as market towns that act as a service center for a surrounding rural community; all three locate in relatively close proximity to major population centers; and all three are (to a degree) transit stops between those large population centers and iconic tourism destinations of international repute. A summarized comparison of site characteristics is presented in Table 1 below.

\section{METHOD}

This article investigates the interface between expert opinion and community attitude through a two-stage process that included a series of in-depth interviews with a range of identified expert stakeholders in each of the three study sites, and a mail survey of resident attitudes towards the issues that emerged from those interview discussions.

In each of the study sites, contact was initially made with the relevant local government administration for assistance in identifying and securing the cooperation of individuals who were believed to be influential key informants in relation to local tourism policy initiatives - these individuals were typically categorized under the occupational classifications shown in Table 2. Each individual interview was conducted on a face to face basis, modeled on the interview topics also presented in Table 2, with key points being recorded by the interviewer immediately after the conclusion of each conversation.

TABLE 1

Study Site Characteristics

\begin{tabular}{llll}
\hline Criterion & \multicolumn{1}{c}{ England } & Ireland \\
\hline Study Site & Buxton & Waterford & Whangarei \\
Urban population & 25,000 & 45,000 & 45,000 \\
Rural population & 75,000 & 30,000 & 25,000 \\
Economic drivers & Agriculture, tourism & Agriculture, light manufacturing \\
Relative prosperity & Moderate to High & Moderate Agriculture, light manufacturing \\
Iconic visitor attractions & High Peak National Park & Waterford Crystal \\
Nearby urban conurbations & Several, approx. population 15 million & Dublin, 1.4 million \\
Nearby tourism icons & Several & Ring of Kerry \\
Level of tourism activity & Moderate to high & Low to moderate \\
\hline
\end{tabular}


TABLE 2

Expert Interview Framework

\begin{tabular}{ll}
\hline Criterion & \multicolumn{1}{c}{ Comment } \\
\hline Key Informant & - Local government politicians with a special \\
Sources & interest in tourism development \\
- Executives of public sector regional & development agencies \\
- Executives of regional and local tourism & boards \\
- Executives of private sector chambers of & commerce \\
- Managers of major local tourism businesses \\
- Representatives of major local employers \\
- Senior academics from tertiary education \\
institutions \\
- Assessment of interviewee's role in tourism \\
planning and development \\
- Views on visitor impacts on the local \\
economy, environment, lifestyle \\
- Cost-benefit analysis of future tourism \\
development \\
- Assessment of scope and scale of current \\
visitor activity in the community \\
- Opinion on desirability of future growth in \\
visitor activity \\
- Identification of missed opportunities and \\
under-estimated threats \\
- Confidence in regional administration's \\
ability to effectively manage the process \\
\hline
\end{tabular}

As a result of these interviews, it was possible to establish eight key policy statements that could usefully be applied as tests of desirability in terms of future tourism development, and to establish an expert level of agreement/ disagreement, measured on a seven-point Likert-style scale, with each statement:

1. Visitors have a generally positive impact on the local economy.

2. Visitors have a generally positive impact on the local lifestyle.

3. Visitors have a generally positive impact on the local environment.

4. More visitors lead to improved facilities for local people.

5. More visitors lead to enhanced wealth for local people.

6. We should therefore develop more facilities for visitors.

7. We should encourage higher levels of visitation.

8. Careful planning can overcome the negative impacts of increased visitation. 
In order to obtain comparative data from a sample of local residents, it was decided to reject the adoption of any previously validated scale-notable options were those developed by Lankford \& Howard (1993) and Ap \& Crompton (1998) — in favor of a direct test of respondents' level of agreement with the eight statements presented above. This approach reflected our belief that the current research did not set out to gather resident opinion per se, but rather sought to assess the attitudes and beliefs of a range of case study communities in comparison with expert perspectives and perceptions. As such, the advantages of simplicity offered by an eight-item survey were thought to outweigh the greater reliability available through adoption of a more complex instrument.

Each of the eight principles of tourism development was therefore addressed by a seven point Likert-type evaluative question, anchored by "completely disagree” as score option 1 and "completely agree” as score option 7. The survey was completed by the addition of demographic questions to establish respondents' place of birth, length of community residence, gender, age, education level, personal participa-tion in a tourism-related occupation, and income.

The Irish and New Zealand versions of the instrument were mailed to 1,000 individuals randomly selected from the relevant register of electors, with a request to complete and return within a ten-day time span. The survey was accompanied by a reply-paid return envelope, and an incentive to complete was offered in the form of shopping or petrol vouchers to a randomly drawn respondent. At the English site, due to localized resource constraints, the survey was conducted through the implementation of an intercept interview process with patrons of a major shopping mall located in the heart of the community concerned. A random sampling process was used, at a fixed spatial location within the shopping mall, to generate 147 usable responses, reflecting the originally anticipated 15 percent response rate to the mail survey process used in the Irish and New Zealand locations.

In these latter locations, we did entertain an initial suspicion that both communities may have potentially displayed an element of "survey fatigue," through being subjected to a relatively high number of social science research inquiries in recent years. However, the 21 percent response rate achieved in both communities was well in excess of expectations, and this did create an imbalance between the number of responses received in these two communities and the number received in Buxton - this imbalance is further discussed in a later section of the article. A summary of the overall and sectional response statistics is shown in Table 3 below.

Data collected via this process were evaluated through the application of SPSS software, and the following statistical processes conducted:

- calculation of basic descriptive statistics for the sample and each sub-sample

- calculation of mean response to the eight principles of tourism development

- application of Analysis of Variance (ANOVA) to iden-tify significant differences within and between resident groups

- informal identification of any apparent opinion differ-ences between each expert-resident "pair." 


\section{RESULTS}

The primary descriptive statistics associated with respondent results are shown in Table 4, below, with responses to each of the eight evaluative questions shown as an overall (expert and resident) mean and as separate means for each of the three study sites.

Acknowledging the difficulties inherent in producing statistically rigorous comparisons between small-sample expert opinion and larger-sample resident opinion, Table 5 uses an arbitrary benchmark positioning of "respondent data plus or minus 10 percent" to identify the primary sources of apparent difference.

TABLE 3

Survey Response Statistics

\begin{tabular}{lcccc}
\hline Criterion & England & Ireland & New Zealand & Overall \\
\hline Surveys included & 147 & 217 & 211 & 575 \\
Male/female & $30 \%-70 \%$ & $46 \%-54 \%$ & $40 \%-60 \%$ & $40 \%-60 \%$ \\
Mean age (years) & 42.12 & 43.18 & 53.04 & 46.43 \\
Mean education level (1-6 scale) & 2.64 & 3.07 & 2.89 & 2.90 \\
Employed in visitor-related occupation & $83 \%$ & $32 \%$ & $26 \%$ & $43 \%$ \\
Income level (1-7 scale) & 1.87 & 2.75 & 3.14 & 2.53 \\
\hline
\end{tabular}

TABLE 4

Summarised Results

\begin{tabular}{|c|c|c|c|c|c|}
\hline Visitor Criterion (maximum agreement $=7.00$ ) & & England & Ireland & New Zealand & Overall \\
\hline \multirow[t]{2}{*}{ Visitors are economically positive? } & Expert & 4.85 & 4.00 & 4.68 & 4.53 \\
\hline & Resident & 6.07 & 6.14 & 5.99 & 6.07 \\
\hline \multirow[t]{2}{*}{ Visitors are lifestyle positive? } & Expert & 5.00 & 4.50 & 4.40 & 4.63 \\
\hline & Resident & 5.18 & 5.18 & 5.13 & 5.16 \\
\hline \multirow[t]{2}{*}{ Visitors are environmentally positive? } & Expert & 4.42 & 3.34 & 4.64 & 4.09 \\
\hline & Resident & 5.01 & 5.22 & 5.09 & 5.12 \\
\hline \multirow[t]{2}{*}{ Visitors create improved local facilities? } & Expert & 4.43 & 4.25 & 4.38 & 4.32 \\
\hline & Resident & 3.80 & 4.46 & 4.49 & 4.30 \\
\hline \multirow[t]{2}{*}{ Visitors enhance local (individual) wealth? } & Expert & 3.71 & 3.55 & 3.86 & 3.63 \\
\hline & Resident & 4.35 & 3.75 & 3.81 & 3.93 \\
\hline \multirow[t]{2}{*}{ We should develop more visitor facilities? } & Expert & 5.14 & 4.75 & 4.87 & 5.11 \\
\hline & Resident & 5.98 & 5.67 & 6.35 & 6.11 \\
\hline \multirow[t]{2}{*}{ We should encourage more visitors? } & Expert & 5.29 & 5.05 & 5.02 & 5.14 \\
\hline & Resident & 5.56 & 6.23 & 5.99 & 5.97 \\
\hline \multirow[t]{2}{*}{ Good planning can obviate problems? } & Expert & 3.14 & 3.20 & 3.88 & 3.43 \\
\hline & Resident & 5.60 & 6.30 & 5.99 & 6.01 \\
\hline
\end{tabular}


TABLE 5

Apparent Opinion Differences

\begin{tabular}{|c|c|c|c|c|}
\hline \multirow[b]{2}{*}{ Visitor Criterion } & England & Ireland & New Zealand & Overall \\
\hline & \multicolumn{4}{|c|}{ (residents" relative optimism shown as " $O$ "; pessimism shown as " $P$ ") } \\
\hline Visitors are economically positive & o & o & o & o \\
\hline Visitors are lifestyle-positive & Neutral & O & o & $\mathbf{O}$ \\
\hline Visitors are environmentally positive & o & o & Neutral & o \\
\hline Visitors create improved local facilities & $\mathbf{P}$ & Neutral & Neutral & Neutral \\
\hline Visitors enhance local (individual) wealth & O & Neutral & Neutral & Neutral \\
\hline We should develop more visitors facilities & o & o & o & o \\
\hline We should encourage more visitors & Neutral & O & O & O \\
\hline Good planning can obviate problems & o & o & o & o \\
\hline
\end{tabular}

\section{DISCUSSION}

It seems reasonable to suppose that residents are strongly positive about the historical impacts of past visitor activity, and equally enthusiastic about future prospects for an expanded visitor industry. For the three historical impacts variables (economic, lifestyle, and environmental implications) and the two futures variables ("develop more visitor facilities" and "encourage more visitors"), calculated over the entire data set of 575 responses, there is a relatively nar-row band of supportive opinion ranging from a minimum approval rating of 5.12 for "visitors are environmentally positive" to a maximum of 6.11 for "we should develop more visitor facilities."

These approval ratings are largely consistent across all three study sites, with ANOVA results showing significant differences only in the area of desire to encourage more visitors, where English respondents were less likely to support higher levels of visitation $(F=3.139, p<.001)$. This may reflect the English site's more extensive experience with relatively large scale tourism, for a significantly higher proportion of Buxton respondents acknowledged their direct employment in a visitor-related occupation. If greater personal involvement does lead to reduced enthusiasm for future growth, this may in effect be an example of experiential learning among the residents of that community-greater familiarity in this instance may not necessarily have bred contempt, but it certainly does appear to be generating caution.

In this context, there is some evidence to suggest that residents of all three study sites attach slightly greater importance to the perceived economic impacts of increased visitation than they do to the costs and benefits related to either lifestyle or environment. When responses to the three historical impacts variables - economic, lifestyle, and environmental-are correlated against the two future-oriented variables, there is a moderate degree of linkage between perceived economic benefit and "we should encourage more visitors", with a Pearson coefficient of .552 recorded. Compa-rable correlations for "lifestyle positive" and "environmentally positive" were .450 and .465 , respectively, and the correlations of economic, lifestyle, and environmental impacts per-ceptions with "we should develop more visitor facilities" were .500, .424 , and .447 . 
Even in England, community responses are uniformly more optimistic than the expert view. An unweighted mean of means comparison of all 575 community residents was 5.33, some 22 percent higher than the expert view of 4.36. This "margin of optimism" was most clearly evident in Ireland, where resident ratings were 31 percent higher than comparable expert ratings, while the parallel figure for New Zealand was 20 percent and England 15 percent. This differential can be clearly seen in the 32 cells of Table 5, in which residents were more positive than experts on 22 occasions, with no significant opinion difference noted nine times. The sole example of relative pessimism was represented by the English view of the degree to which visitors may initiate the creation of improved local facilities. Again, this may reflect a frequently expressed frustration among Buxton respondents, that the continued annual growth in visitor numbers has not been accompanied by any perceptible improvements in the public sector infrastructure that forms the centrepiece of visitor appeal for the town.

The third noticeable interpretation suggests that residents may be much more positive about the visitor industry's potential to generate collective benefits to community, as opposed to personal benefits for self. Though English respondents were ambivalent in this regard-one instance of relative optimism, one of relative pessimism-responses from the other two sites to the variables "visitors create improved local facilities" and "visitors enhance local (individual) wealth" were similar to the somewhat lukewarm approval ratings generated by the experts' view.

Finally, the single largest demonstration of opinion variance was exhibited in relation to the variable "good planning can obviate problems," with the overall commu-nity view recording a mean of 6.01, fully 75 percent higher than the expert mean of 3.43. This margin of optimism was again highest in Ireland, where the resident figure exceeded the expert evaluation by 97 percent, while the comparative figure for England was 78 percent and for New Zealand 50 percent. Clearly, those who have traditionally enjoyed minimal involvement in the planning process display much more confidence in that process than those who have typically been required to implement it.

These findings are of course developed from a data set that largely reflects the outcomes of a survey with a relatively low response rate. In this respect, we acknowledge the commonly experienced discrepancy between the type of "ideal world" response rates frequently achieved in the early days of social science research, and the more recent experiences of researchers working with a population that has become inured to the wide range of (both academic and commercial) social surveys currently in progress. This limitation to reliability and validity is exacerbated by the response imbalance in favor of Waterford and Whangarei, though a conscious decision was made to reject any data manipulation to increase the weighting of Buxton opinion. Again, the focus here was on the measure of comparative rather than independent attitudes, and any weighting adjustment would have had little effect on the relationship between Buxton expert opinion and Buxton resident opinion.

So, do these results indicate over-optimism among residents, especially Irish residents, excessive caution among the experts, or a combination of both elements? In an attempt to address these questions, the outcomes of comparative data analysis are summarized by means of the two position statements offered below: 
- Expert opinion relating to the visitor industry is historically based, with the experts' past experience suggesting that the industry may offer mild economic benefits, moderate lifestyle benefits, and considerable environmental costs. It is however difficult to reconcile these modest appraisals with the positive approval ratings subsequently awarded to the prospect of more visitor facilities and greater visitor numbers, and it is thus tempting to conclude that the voice of experience may also be the voice of vested interest - those whose opinions are valued as expert advisors may often also be those who will benefit most from expanded visitor industry activities.

- Resident opinion relating to the visitor industry is largely based on the future, with a degree of naivety, or at least inexperience, generating a rose-colored glasses perspective that anticipates significant benefits and negligible costs. Importantly, there is little overt suggestion of individual self-interest in this resident opinion for, as has been previously noted, respondents are much more confident in the potential for community benefits as opposed to individual benefits. In essence, the community voice is just that, the voice of community.

How then can these quite different perspectives be effectively reconciled? This is an important question, for expert-resident opinion difference in these three study sites is marked. For the experts, the visitor industry is seen as one that requires careful management, and one in which over-enthusiastic expansion has, in the past, proven to be irretrievably damaging; for residents, the industry does appear to offer far more in the way of benefits than it does in the way of costs. Thus, for these residents, widely held and strongly positive attitudes can quickly translate into impatience and frustration with what may be seen as an unduly cautious pattern of progress. This, then, is the point at which local government politicians might typically choose to become involved.

In Figure. 1, the political element of community adminis-tration was conceptualized as two separate identities - from an expert perspective as the "representatives of the people"; and from a community perspective as the "supervisors of the experts." Though there is clearly an element of accuracy in both of these personifications, perhaps the real value of an elected political body is as a bridge between two divergent bodies of opinion that might otherwise be consigned to an ever-deepening entrenchment of relative positions. In essence, then, the elected members' body would appear to have a valid role to play at both ends of the opinion scale-to ensure that the expert cohort are made fully aware of the scope and scale of community feeling in relation to devel-opment initiatives such as this; and to ensure that community opinion is adequately informed by an effective public information service. If there is in fact an objective right answer to the cost-benefit balance associated with visitor industry development (which is by no means certain), it is intuitively likely to occupy some middle ground between the two positions identified in this research. If politics is indeed the art of the possible, then there is likely to be a political role in the resolution of those opinion differences.

\section{CONCLUSIONS}

Recent developments in the mainstream philosophy of local government administration has led to a greater awareness of the roles to be played by expert public servants, elected politicians, and individual and collective community representatives. This article has described the types of 
interaction, and opinion differences, that can arise when these three separate roles and their associated perspectives are brought to bear on a specific element of local development policy.

The results of research from three entirely discrete communities suggest that there is a considerable degree of consistency in the manner by which these relationships evolve-what is true for England and Ireland is, to a large extent, equally true for New Zealand. As such, though perceptibly influenced by variation in residents' past exposure to visitor industry activity in their towns, there is a consistent air of optimism amongst local people for an expansion of visitor activity, and an equally consistent note of caution sounded by those with expert status and planning advisory roles. This finding is however complicated by a largely convergent view of the desirability of future industry expansion, possibly motivated by an expert's concern for self and a resident's concern for community. This is indeed a complex pattern, and one that is further complicated by clearly divergent stakeholder appraisals of the capacity for communities to successfully manage and control that expansion.

The ultimate responsibility for appropriate visitor industry development is of course held by communities themselves, and it is here that the roles assigned to each of the three identified stakeholder groups become vital. In this context, is it really so surprising that ordinary residents of ordinary communities should be so optimistic about something that is new to them, that has a palpable allure of glamour and excitement? Conversely, is it so surprising that professional public servants, accustomed to the entrenched allocation of local strategic planning responsibilities, should habitually choose to err on the side of caution? For the authors of this paper, these are both rational and predictable perspectives.

What then of the third corner of the strategic policy triumvirate, what is the most appropriate positioning for the political persona? This article has concluded that the most appropriate answer to this question lies with the building of political bridges between experts and residents, with an interpretation of the political role as one of facilitation rather than leadership. Thus, in an ideal world, the political establishment will have made the permanent expert body fully and accurately aware of the direction and strength of community opinion; and will have simultaneously ensured that the community was advancing opinions and promoting subsequent actions that were as much as possible based on high-quality information.

If that situation were to evolve in practice, there is of course no guarantee that the best decisions would be taken, and the optimum choices made. It would however be reasonable to expect that there would be a greatly enhanced degree of shared responsibility for the decisions made, and shared acceptance of whatever consequences might ensue. That in itself would represent a significant step forward for many local communities.

\section{REFERENCES}

Ap, J., and Crompton, J.L. (1998). Developing and testing a tourism impact scale. Journal of Travel Research, 37(2), 120-130.

Barbaro, G. (2006). Defining realities: Why community consultation needs to start with the problem, not the solution. Journal of Communication Management, 10(1), 44-54.

Donnelly, M. (1999). Making the difference: Quality strategy in the public sector. Managing 
Service Quality, 9(1), 47-52.

Fagan, M.H. (2006). Exploring city, county and state e-government initiatives: An East Texas perspective. Business Process Management Journal, 12(1), 101-112.

International Association for Public Participation (2007). IAP2 Spectrum of Public Participation. Retrieved Sept. 1, 2008, from http://iap2.org/associations/4748/files/IAP2percent20Spectrum_vertical.pdf

Lankford, S.V., and Howard, D.R. (1993). Developing a tourism impact attitude scale. Annals of Tourism Research, 21(1), 121-139.

Newton, K., and van Deth, J.W. (2005). Foundations of comparative politics: Democracies of the modern world. Cambridge, UK: University Press.

Reddel, T. (2004). Third way social governance: Where is the state? Australian Journal of Social Issues, 39(2), 129-142.

Reddel, T., and Woolcock, G. (2004). From consultation to participatory governance? A critical review of citizen engagement strategies in Queensland. Australian Journal of Public Administration, 63(3), 75-87.

Saunders, J. (2002). 'A quiet revolution: Opportunities for local futures in the UK. Foresight, $4(2), 10-20$.

Silver, D., Weitzmann, B., and Brecher, C. (2002). Setting an agenda for local action: The limits of expert opinion and community voice. Policy Studies Journal, 30(3), 362-378. 